\title{
We need a NICE for global development spending [version 1;
}

\section{peer review: 2 approved]}

\author{
Kalipso Chalkidou¹, Anthony J. Culyer (iD) 2,3, Amanda Glassmann ${ }^{4}$ Ryan Li ${ }^{1}$ \\ ${ }^{1}$ Global Health and Development Group, Institute of Global Health Innovation, Imperial College London, London, SW7 2AZ, UK \\ 2Institute of Health Policy, Management and Evaluation, University of Toronto, Toronto, ON, M5T 3M6, Canada \\ ${ }^{3}$ Department of Economics \& Related Studies, University of York, York, YO10 5DD, UK \\ ${ }^{4}$ Center for Global Development, Washington, DC, 20036, USA
}

V1 First published: $25 \mathrm{Jul}$ 2017, 6:1223

https://doi.org/10.12688/f1000research.11863.1

Latest published: $25 \mathrm{Jul}$ 2017, 6:1223

https://doi.org/10.12688/f1000research.11863.1

\section{Abstract}

With aid budgets shrinking in richer countries and more money for healthcare becoming available from domestic sources in poorer ones, the rhetoric of value for money or improved efficiency of aid spending is increasing. Taking healthcare as one example, we discuss the need for and potential benefits of (and obstacles to) the establishment of a national institute for aid effectiveness. In the case of the UK, such an institute would help improve development spending decisions made by DFID, the country's aid agency, as well as by the various multilaterals, such as the Global Fund, through which British aid monies is channelled. It could and should also help countries becoming increasingly independent from aid build their own capacity to make sure their own resources go further in terms of health outcomes and more equitable distribution. Such an undertaking will not be easy given deep suspicion amongst development experts towards economists and arguments for improving efficiency. We argue that it is exactly because needs matter that those who make spending decisions must consider the needs not being met when a priority requires that finite resources are diverted elsewhere. These chosen unmet needs are the true costs; they are lost health. They must be considered, and should be minimised and must therefore be measured. Such exposition of the trade-offs of competing investment options can help inform an array of old and newer development tools, from strategic purchasing and pricing negotiations for healthcare products to performance based contracts and innovative financing tools for programmatic interventions.

\section{Keywords}

Value for money, aid, transition, cost-effectiveness, health technology assessment, priority setting, universal coverage

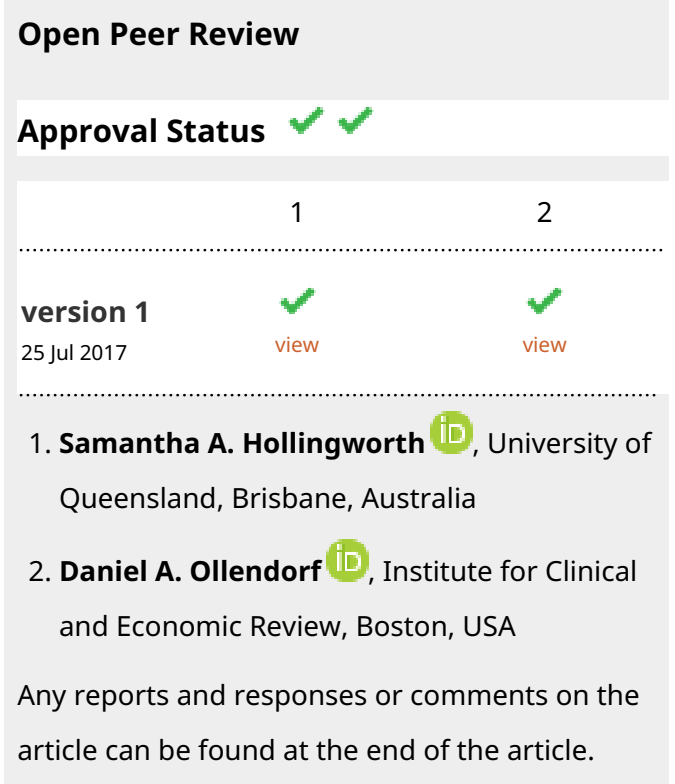


Corresponding author: Kalipso Chalkidou (kalipso.chalkidou@imperial.ac.uk)

Author roles: Chalkidou K: Conceptualization, Writing - Original Draft Preparation, Writing - Review \& Editing; Culyer AJ: Writing Review \& Editing; Glassman A: Writing - Review \& Editing; Li R: Writing - Review \& Editing

Competing interests: No competing interests were disclosed.

Grant information: This work was supported by a grant from the Bill and Melinda Gates Foundation [OPP1134345] and the UK's Department for International Development.

The funders had no role in study design, data collection and analysis, decision to publish, or preparation of the manuscript.

Copyright: ( $) 2017$ Chalkidou K et al. This is an open access article distributed under the terms of the Creative Commons Attribution License, which permits unrestricted use, distribution, and reproduction in any medium, provided the original work is properly cited.

How to cite this article: Chalkidou K, Culyer AJ, Glassman A and Li R. We need a NICE for global development spending [version 1; peer review: 2 approved] F1000Research 2017, 6:1223 https://doi.org/10.12688/f1000research.11863.1

First published: 25 Jul 2017, 6:1223 https://doi.org/10.12688/f1000research.11863.1 


\section{Aid is wasted}

Up to $40 \%$ of healthcare spending is wasted according to the World Health Organization (WHO; (World Health Organization, 2010)). A recent report by the Organisation for Economic Cooperation and Development puts healthcare waste - defined broadly as overutilisation of technologies, unwarranted hospital admissions, corruption and inefficient pharmaceutical markets - at 20\% (OECD 2017). WHO analysis suggests that even the poorest or most fragile states in Sub Saharan Africa rely on external funding for less than a quarter of their total healthcare spending, and in all bar a handful the trend shows a rising domestic over foreign spending (Soucat, 2017). By implication, a lot of healthcare aid money does not buy health, while even the world's poorest countries increasingly finance their healthcare systems (whether wastefully or efficiently) out of extremely limited domestic resources.

None of this means that more external money for development is now unimportant, but what matters, at least as much as the amount of aid, is what Glassman (2015) calls the "priorities ditch": a dearth of investment in governance know-how for setting spending priorities locally, and in better incentives that link aid investment to development results, in a context-sensitive and hence more effective manner (Glassman \& Chalkidou, 2012). There are lots of things donors can do, but don't do, to fill this governance gap and to create the capacities (both internally and within countries) for wise spending, and, where countries are within reach of the Sustainable Development Goals, to smooth a transition to a world less dependent on aid.

\section{Filling the priorities ditch}

Given today's aid scepticism in major funding nations, credible mechanisms that actually deliver better development outcomes whether poverty reduction, health, sanitation, nutrition, education, upholding of human rights - for the poorest and most vulnerable people must surely be our priority. The dramatic proposed cuts in the USAID budget (Konyndyk, 2017) and the reluctant UK commitment to a $0.7 \%$ GDP aid spending target reflect public scepticism of the return-on-investment of aid. The numerous channels through which UK aid is distributed also suggest multiple objectives and a lack of strategic purpose and coordination: the Department for International Development (DFID), Foreign and Commonwealth Office, UK Trade, Research Councils, Commonwealth Development Corporation, Ministry of Defence, etc. The scepticism is shared by some sections of the UK popular media and Parliament. It ought to be possible to moderate such scepticism: a loud and clear commitment by the US and UK administrations to ensuring that money spent on aid is money well spent, good value for those giving and for those receiving. Emphasis on analysis, evidence and performance, rather than evidence-free advocacy and non-performance-linked targets, may be a win-win for both donors and recipients of aid (Chalkidou et al., 2017). But this will require a much sharper focus within major global donors and - most importantly - in-country training in the necessary analytical skills and in-country infrastructure for recipients, so that competent agencies and ministerial departments are created and sustained (Li et al., 2017).

To make the case, it is no use relying solely on emotional case-by-case appeals to "doing the right thing" or on a parade of advocacy-friendly global statistics. Instead, before any funds are committed, donor countries should insist that the necessary capacity in recipient countries is brought into being to ensure that only cost-effective investments are considered in the first place. Mere effectiveness is not enough. The only relevant kind of cost-effectiveness is that determined by the social values and development objectives (better health, better education, and so on) in the country, the budget it proposes, and the associated realistic cost-effectiveness threshold, above which not a single significant investment should be made without very compelling reasons. A serious and sustained institutionalised effort is needed to analyse and publish every significant aid programme's return-on-investment, monitoring and evaluating it both during implementation and in the longer run. Ian Mitchell of the Center for Global Development proposes that any bilateral aid programme above $£ 10 \mathrm{~m}$ should be disallowed unless this kind of analysis has been done and the proposed investment passes the relevant tests (Mitchell, 2017). He also proposes the establishment of NIDE, a National Institute for Development Effectiveness, to play this role on behalf of the UK.

\section{NIDE: NICE for aid?}

Modelled along the lines of the National Institute for Health and Care Excellence (NICE), NIDE would be an independent public body accountable to the Government, and whose function is to assess the value-for-money of overseas development assistance on behalf of DFID and other relevant agencies. NIDE would evaluate the value-for-money of investing in aid not only for bilateral programmes, but also for monies spent through multilateral agencies - in health aid, such agencies include the Global Fund for AIDS, TB and Malaria, UNITAID, and Gavi - where the opportunities for efficiencies, given the bulk purchasing of commodities on behalf of large part of the world, are significant. Indeed, Her Majesty's Government made a start in this direction with last September's Performance Agreement with the Global Fund: "Through our membership of the Board of the Global Fund, the UK will work to strengthen independent advice and scrutiny of the Global Fund to ensure that it is following best practice in seeking value for money." (Department for International Development and The Global Fund to Fight Aids, Tuberculosis and Malaria, 2016). What are missing, and what a NICE-for-aid could provide, are value-for-money indicators and valid, reliable processes for measuring and reporting against them.

NIDE would also determine two other key factors in conjunction with government departments of recipient countries. One is the nature of criteria other than cost-effectiveness to be deployed to inform investment decisions. For health investments, evident candidates include the benefits of financial protection that the investments may enable and the contribution the investment would make to reducing the worst inequalities in health. The other factor is the cost-effectiveness threshold suitable for each client country, set so that when the country eventually absorbs the costs of whatever investments the aid has established (for instance, vaccination programmes), those costs are affordable with domestic resources, and in the case of health not the absurdly generous thresholds inherited from past WHO priority-setting (Culyer, 2016; Revill et al., 2014). NIDE would need also to play a key role in the creation of training and capacity-building programmes - targeting a broad spectrum of stakeholders ranging policymakers, technical officers, researchers, 
and the like - and preferably such programmes located in recipient countries and preferably ones that also train trainers, thereby avoiding as far as possible excessive ongoing dependence on the UK and other high-income countries (Li et al., 2017).

The "NICE-for-aid" idea is not new for public policy, at least not in the UK. The What Works Centres claim "a world first" for any government to have "...taken a national approach to prioritising the use of evidence in decision-making." (Ruiz \& Breckon, 2014). What Works Centres span health (NICE is part of the What Works network), crime, education and ageing, but do not (yet) cover development. The NIDE proposal simply extends this world innovation in public policy to overseas development assistance. This ought to win over domestic aid sceptics by championing strong governance and institutions in recipient countries alongside rigorous value-for-money assessments - assessments using world class skills, which the UK prides itself on and has in abundance (Hasan et al., 2015).

NIDE must not be a patronising or culturally imposing exercise. The BMGF, Rockefeller and DFID already fund the international Decision Support Initiative (iDSI) based at Imperial College. This is a multinational, multiprofessional and multidisciplinary initiative aiming at improving health resource allocation decisions in low and middle income countries (LMICs) using evidence of comparative clinical and cost-effectiveness (Chalkidou, et al., 2017). It operates by strengthening local capacities for decision-making and priority-setting, by promoting best practice in analytical and statistical methods, and by sharing experiences and results actively through its expanding network. iDSI works with the national governments or national health insurers of India, South Africa, Ghana, Indonesia, Vietnam and China to improve value-for-money in healthcare investments. The World Bank is coordinating a Joint Learning Network for Universal Health Coverage, which is somewhat broader in scope and has recently launched an efficiency collaborative with similar objectives to those of iDSI. And whilst demand from governments for such support is less evident in low income economies, funding channels, such as the Global Fund and UNITAID, can play this role. In its market shaping strategy, the Global Fund commits to: “...proactively engage with recipients to share relevant analyses and information about likely product costs and comparative health technology assessments...the GF Secretariat...will connect recipients with these resources to inform country-driven health technology assessment. Engaging in this process can also be an opportunity to build country capacity for health technology assessment and how to incorporate this into product selection decisions." (Kanpirom et al., 2017).

\section{NICE for aid: Setting it up}

Setting up a NICE-for-aid would hardly be an easy task. There are challenges in setting the scope (health, education, other areas of social policy, commodities or services, etc.) and in defining (even inventing) the methods to be followed for evaluating aid investment projects both ex ante, and perhaps ex post in monitoring and evaluation, where perhaps much of the ODA Research Council money could be channelled.
On scope, healthcare spending is an obvious starting point given the global drive for universal health coverage - Target 3.8 of the Sustainable Development Goals. Within healthcare, NIDE should seek a broad agreement on the value of evidence and the principles according to which evidence would be appraised; on the principles for determining value-for-money (economic efficiency); on suitable outcome measures and their appropriate uses; and on the principles to be used in assessing ethical and distributional issues and their integration into Health Technology Assessment (Chalkidou et al., 2016). NIDE should also make an inventory of the evidence-based policy expertise - essentially expertise in evidence generation, governance, and policy - that the UK has after the Cochrane Collaboration, more than 15 years' experience of NICE, and two decades of Health Technology Assessment. NIDE should also liaise with the National Institute of Health Research and the Research Councils to develop a research programme that addressed important unanswered but researchable questions - ones whose answering would enhance NIDE's effectiveness.

On methods, starting with articulating a Reference Case, that is an agreed "gold standard" for conducting and reporting economic analyses, to drive better economic evaluations makes sense. iDSI already has a Reference Case for health economic evaluations in low- and middle-income countries (Wilkinson et al., 2016). A Reference Case would have two main tasks: first to list the essential characteristics of competent research and research reporting, and second to list those specific contextual matters that can be resolved only in-country. NIDE could usefully revisit the current DFID definition of Value for Money (which has little economic content), the 4Es framework, which confusingly comprises 3 Es and a fourth CE for cost-effectiveness - but inexplicably discusses neither opportunity costs nor allocative efficiency (Department for International Development, 2011).

NIDE should avoid taking a blinkered approach on the scope of economic and epidemiological analyses. They provide useful tools for looking at countries transitioning away from aid, to inform, for instance, appropriate co-financing levels to maximise returnon-investment. Recent work has advanced the field of efficiency and performance measurement of whole healthcare systems (Smith \& Yip, 2016), moving well beyond the NICE approach of assessing only individual pharmaceutical products to include the analysis of delivery platforms, health system strengthening interventions and human resource constraints (van Baal et al., 2017; Morton et al., 2016). This is not easy - a recent attempt at dealing with a DFID programmatic intervention on maternal and child health in Nigeria as a technology whose value could be assessed compared to the next best thing, proved to be incredibly hard (Jones, 2017). Hard - but not impossible. Hard - but in fact essential if such investments are not to waste aid money. At the very least, the Nigeria study threw up areas where more research, empirical or methodological, or data collection exercises, or investment in skills were needed.

Data is another important prerequisite for systematically assessing the value for money of aid interventions. Systematic assessment is 
not only valuable for the substantive implications it has for particular policy choices; it also identifies data gaps and focuses attention on future data collection priorities amongst types of information that would make a difference in future investment decisions. Data on unit costs (price transparency is one important element of this) and resource use (how much does it cost the National Health Insurance of Ghana to treat a stroke?), incidence (how much of the full cost falls on private individuals), individual and social preferences (reflecting local cultural and religious realities), data on risks (incidence data for most conditions for example are absent for most SSA countries) and effect sizes (inevitably based on pragmatic research carried out in in-country context; (BOLDER Research Group, 2016)), treatment of residual uncertainty (for example, where data are absent and resort has to be had to modelling and "expert opinion"). Such a targeted, decision needs-driven approach to data generation, ideally through systems' own routine mechanisms, need not necessarily be complemented by monster demographic health surveys, but it would make decisions easier to make, the reasons for them clearer, and decision makers more accountable to their populations and their donors. NICE has had that very effect in the National Health Service (NHS): costing data on technologies and services (like reference costs and later diagnosis-related groups) became more readily available as NICE used them for informing real investment decisions.

\section{The opposition?}

NIDE is bound to provoke hostility. If it does things wrong, this will be deserved. But let us review a few grounds that would not be good grounds for complaint.

It will be said that costs ought not to be considered when setting health care priorities (Loewy, 1980). Only need matters. The charge is deeply wrong because it is inconsistent. It is exactly because needs matter that NIDE must consider the needs not being met when a priority requires that resources go elsewhere. These chosen unmet needs are the true costs. They are lost health. They must be considered, and should be minimised (and must therefore be measured).

It will be said that people's willingness to pay ought not to determine the priorities in a public health insurance system because of the huge inequalities in abilities to pay in most LMICs. Indeed, individual willingness ought not to be the determinant. But explicit collective willingness to pay is essential, this is most handily expressed by a cost-effectiveness threshold and NIDE will have to help countries to decide what this should be. The WHO's 1-3 times GDP per capita for health may well have caused more harm than good, until its quiet withdrawal by WHO sometime in 2016/17, for being overly generous and not nearly country specific enough to inform meaningful local spending decisions (Revill et al., 2014; Woods et al., 2016). Here is an issue over which one size definitely does not fit all. In particular, setting a threshold that is too high ensures that it becomes impossible to implement a cost-effective programme of care. It ensures that services recommended on its basis are unaffordable.

Some will rail against economics and economists, attributing to them an indifference to inequities and uncritical worship of market solutions. Major figures in global development have attributed inequalities in healthcare outcomes and access to economics and economics. "Value for money", "sustainability", a "minimum healthcare package" and "limited resources" are deemed to be too un-aspirational and depriving the poor in developing countries from services they need, in the name of efficiency (Paul Farmer, Who Lives and Who Dies; (Farmer, 2015)). Senior WHO officials recently declared any efforts to value benefits of the latest expensive on-patent drugs, or "the value of life", simply "unfeasible". And economists are accused of "institutionalising inequality" and being collectively against "access free at the point of delivery", which "kills the soul of an economist" (Richard Horton, The Atlantic, 2012) (Meyer, 2013). There are of course some economists who (still) believe in healthcare markets, consumer supremacy and prices as the best proxies for people's preferences, all ill-suited to healthcare and most public policy, but these economists are not amongst those who published the Economists' Declaration on UHC (Summers, 2015). True, NIDE must choose its economists well!

None of these objections should stop the UK from improving the effectiveness of aid spending, starting with its own investment and building on the firm principle that we seek to maximise the impact of our aid money on the health of the people we choose to help. If DFID were to create a NICE-for-aid it would at a stroke improve purchasers' ability to buy effectively at all levels: from the way DFID spends its own money, through bilateral country programmes or organisations such as Global Fund, UNITAID and Gavi, as well as the WHO and the World Bank, to influencing how the likes of the Global Fund or World Bank trust funds contract directly with product manufacturers or pass money on to countries for them to buy from service providers or product manufacturers. Such an approach would give new meaning to "strategic purchasing" or "evidence-informed procurement". It could also inform upstream investment decisions made by the like of DFID's CDC, the UK private investment arm, active in South Asia and Sub Saharan Africa.

\section{What would it cost?}

It has been estimated that the HTA programme in the UK has much more than paid for itself. Implementing just ten reports of the hundreds produced, for only one year, and conservatively assuming a yield of just $12 \%$ of the total benefit assumed in the HTA analyses, generates enough value to cover the running of the whole HTA programme for 20 years (Guthrie et al., 2016). That is surely a return-on-investment to die for. NICE, one of the most expensive of HTA agencies in the world, costs less than $0.05 \%$ of the NHS budget. A review of priority setting institutions around the world found that those countries who do have them, spend less than 1/1000 of their resources on them (Glassman et al., 2012). Spending less than $0.1 \%$ of the total health care budget on deciding how to spend the remaining $99.9 \%$ more wisely, improving outcomes and access, and building the needed local technical and administrative capacity in the process, is surely the definition of a good investment.

\section{....and without a NICE-for-aid?}

What is the alternative? The risk is that the UK's (and possibly USA's) aid spending becomes increasingly vulnerable to sceptics, 
leading to further budget cuts, and further fragmentation between spending channels across government departments. The "business as usual" approach would rule: serving short term objectives rather than maximising long term impact on reducing poverty and jeopardising progress toward valuable development goals, such as universal health coverage. Without the work a NIDE could do, countries transitioning away from aid will become more at risk of regressing back to being aid-dependent states, the local intelligent capacity for making good decisions will remain unbuilt, and the world risks losing hard won gains towards sustainable global development (Glassman \& Temin, 2016). It can be done. Let's do it!

\section{Competing interests}

No competing interests were disclosed.

\section{Grant information}

This work was supported by a grant from the Bill and Melinda Gates Foundation [OPP1134345] and the UK's Department for International Development.

The funders had no role in study design, data collection and analysis, decision to publish, or preparation of the manuscript.
BOLDER Research Group: Better Outcomes through Learning, Data, Engagement, and Research (BOLDER) - a system for improving evidence and clinical practice in low and middle income countries [version 1; referees: 2 approved]. F1000Res. 2016; 5: 693.

PubMed Abstract | Publisher Full Text | Free Full Text

Chalkidou K, Glassman A, Marten R, et al:: Priority-setting for achieving universal health coverage. Bull World Health Organ. 2016; 94(6): 462-467. PubMed Abstract | Publisher Full Text | Free Full Text

Chalkidou K, Li R, Culyer AJ, et al:: Health Technology Assessment: Global Advocacy and Local Realities; Comment on "Priority Setting for Universal Health Coverage: We Need Evidence-Informed Deliberative Processes, Not Just More Evidence on Cost-Effectiveness." Int J Health Policy Manag. 2017; 6(4); 233-236.

Publisher Full Text

Culyer AJ: Cost-effectiveness thresholds in health care: a bookshelf guide to their meaning and use. Health Econ Policy Law. 2016; 11(4): 415-32.

PubMed Abstract | Publisher Full Text

Department for International Development: DFID's Approach to Value for Money (VfM). Department for International Development 2011.

Reference Source

Department for International Development and The Global Fund to Fight Aids, Tuberculosis and Malaria: Performance Agreement. United Kingdom and The Global Fund to Fight Aids, Tuberculosis and Malaria. 2016.

Reference Source

Farmer P: Who Lives and Who Dies: LRB 5 February 2015. [Online]. 2015; 37(3): 17-20, [Accessed: 6 June 2017].

Reference Source

Glassman A, Chalkidou K: Priority-Setting in Health: Building Institutions for Smarter Public Spending. 2012.

Reference Source

Glassman A, Chalkidou K, Giedion U, et al.: Priority-setting institutions in health: recommendations from a center for global development working group. Global Heart. 2012; 7(1): 13-34.

PubMed Abstract | Publisher Full Text

Glassman A, Kenny C: In Health Spending, Middle-Income Countries Face a Priorities Ditch, Not a Financing Ditch - But That Still Merits Aid | Center For Global Development. [Online]. 2015, [Accessed: 5 June 2017].

Reference Source

Glassman A, Temin M: Millions Saved: New Cases of Proven Success in Global Health. Center for Global Development. 2016

Reference Source

Guthrie S, Hafner M, Bienkowska-Gibbs T, et al: Returns on Research Funded Under the NIHR Health Technology Assessment (HTA) Programme: Economic Analysis and Case Studies. Rand Health Q. 2016; 5(4): 5 .

PubMed Abstract | Free Full Text

Hasan N, Curran S, Jhass A, et al:: The UK's strong contribution to health globally. Lancet. 2015; 386(9989): 117-118.

PubMed Abstract | Publisher Full Text

Jones A: Integration of iDSI's Reference Case principles for economic evaluation and DFID's approach to value for money analysis. Opportunities and challenges. F1000Res. 2017.

Publisher Full Text

Kanpirom K, Luz AC, Chalkidou K, et al:: How Should Global Fund Use Value-forMoney Information to Sustain its Investments in Graduating Countries? Int $J$ Health Policy Manag. 2017; 6: 1-5.

Reference Source
Konyndyk J: Our First Peek at Trump's Aid Budget: Big Changes, but Will Congress Play Along? Center For Global Development [Online]. 2017, [Accessed: 6 June 2017].

Reference Source

Li R, Ruiz F, Culyer AJ, et al: Evidence-informed capacity building for setting health priorities in low- and middle-income countries: A framework and recommendations for further research [version 1; referees: 2 approved]. F1000Res. 2017; 6: 231.

PubMed Abstract | Publisher Full Text | Free Full Text

Loewy EH: Cost should not be a factor in medical care. N Engl J Med. 1980; 302(12): 697.

PubMed Abstract | Publisher Full Text

Meyer R: Is Economics "The Biggest Fraud Ever Perpetrated on the World?"

The Atlantic [Online]. 2013, [Accessed: 6 June 2017].

Reference Source

Mitchell I: What a UK Election Manifesto on Development Might Look Like: 19 Proposals from CGD. Center For Global Development [Online]. 2017, [Accessed: 5 June 2017].

Reference Source

Morton A, Thomas R, Smith PC: Decision rules for allocation of finances to health systems strengthening. J Health Econ. 2016; 49: 97-108.

PubMed Abstract | Publisher Full Text

OECD: Tackling wasteful spending on health. OECD Publishing; 2017. Reference Source

Revill P, Asaria M, Phillips A, et al:: WHO Decides What is Fair? International HIV Treatment Guidelines, Social Value Judgements and Equitable Provision of Lifesaving Antiretroviral Therapy. CHE Research Paper 99, 2014.

Reference Source

Ruiz F, Breckon J: THE NICE WAY: LESSONS FOR SOCIAL POLICY AND PRACTICE FROM THE NATIONAL INSTITUTE FOR HEALTH AND CARE

EXCELLENCE. Alliance for Useful Evidence. 2014

Reference Source

Smith PC, Yip W: The economics of health system design. Oxf Rev Econ Pol.

2016; 32(1): 21-40.

Publisher Full Text

Soucat A: Building institutions for an effective transition towards UHC.

Sustainability and Transition Meeting. 2017.

Reference Source

Summers LH: Economists' declaration on universal health coverage. Lancet 2015; 386(10008): 2112-2113.

PubMed Abstract | Publisher Full Text

van Baal $\mathrm{P}$, Thongkong N, Severens JL: Human resource constraints and the methods of economic evaluation of health care technologies [version 1; not peer reviewed]. F1000Res. 2017; 6: 468 .

Publisher Full Text

Wilkinson T, Sculpher MJ, Claxton K, et al:: The International Decision Support Initiative Reference Case for Economic Evaluation: An Aid to Thought. Value Health. 2016; 19(8): 921-928.

PubMed Abstract | Publisher Full Text

Woods B, Revill P, Sculpher M, et al:: Country-Level Cost-Effectiveness Thresholds: Initial Estimates and the Need for Further Research. Value Health. 2016; 19(8): 929-935.

PubMed Abstract | Publisher Full Text | Free Full Text

World Health Organization: HEALTH SYSTEMS FINANCING. The path to universal coverage. 2010.

Reference Source 


\section{Open Peer Review}

\section{Current Peer Review Status:}

\section{Version 1}

Reviewer Report 15 August 2017

https://doi.org/10.5256/f1000research.12819.r24491

(C) 2017 Ollendorf D. This is an open access peer review report distributed under the terms of the Creative Commons Attribution License, which permits unrestricted use, distribution, and reproduction in any medium, provided the original work is properly cited.

\section{Daniel A. Ollendorf}

Institute for Clinical and Economic Review, Boston, MA, USA

This is a thought-provoking piece advocating for a quasi-governmental body that uses evidencebased principles to ensure the efficient, cost-effective, and equitable use of donor funds for global health programming directed at low-and-middle income countries. The authors have a wealth of experience in managing the use of international aid monies in the developing world, and been heavily involved in training and implementation of health technology methods and decision support techniques in those settings.

The authors' work with iDSI is instructive, but readers will benefit from specific examples of the change brought about the organization's activities. For example, has an evaluation been performed to compare decision-making processes before and after an iDSI "intervention" in India, Ghana, etc.? I've been recently made aware of an "affordable cancer drugs list" for India - was this an iDSI effort and how has its performance contrasted with prior approaches?

Specific comments are also provided below:

Abstract: just a minor grammatical correction. "...is channeled" should be "are channeled."

Pg 3, column 1, paragraph 3: Proposed cuts to USAID and UK commitments certainly reflect skepticism around return-on-investment, but they also likely reflect the presence of nationalist politics, and this should be mentioned.

Pg 3, column 2, paragraph 3: This seems an opportune place to introduce budgetary impact analysis as a companion effort to cost-effectiveness and related efforts. While successful empiric approaches to setting WTP thresholds will explicitly consider health budgets, BIA can be flexibly defined to address contingencies common in the developing world (e.g., regime change, changes in aid vs. domestic funding balance, etc.)

Pg 4, column 1, paragraph 4: Scope challenges are appropriately noted, and I agree that health spending is a natural starting point. However, it would be useful to see some context around spending challenges across sectors in the developing vs. developed world.

Page 5, column 1, paragraph 1: It's very difficult for me disentangle the very real data needs mentioned from the reality of trying to collect data in these settings. An example of a data 
need that was simply and efficiently addressed in an LMIC would be helpful. The example of NICE's impact is less relevant for me given the resources available in the UK.

Page 5, column 2, paragraph 3: It may be premature to do this, but ROI is both about paying for and sustaining NIDE's activities AND reducing wasteful aid spending. Some estimate of wasteful spending in the UK, and what percentage reduction would essentially pay for NIDE and increase access to health services in some number of countries would be helpful, even if back-of-the envelope.

Is the topic of the opinion article discussed accurately in the context of the current literature?

Yes

Are all factual statements correct and adequately supported by citations?

Yes

Are arguments sufficiently supported by evidence from the published literature?

Yes

Are the conclusions drawn balanced and justified on the basis of the presented arguments? Yes

Competing Interests: No competing interests were disclosed.

Reviewer Expertise: Health technology assessment, health economics, real world evidence

I confirm that I have read this submission and believe that I have an appropriate level of expertise to confirm that it is of an acceptable scientific standard.

Reviewer Report 07 August 2017

https://doi.org/10.5256/f1000research.12819.r24492

(C) 2017 Hollingworth S. This is an open access peer review report distributed under the terms of the Creative Commons Attribution License, which permits unrestricted use, distribution, and reproduction in any medium, provided the original work is properly cited.

\section{Samantha A. Hollingworth}

School Pharmacy, University of Queensland, Brisbane, QLD, Australia

This interesting paper argues the case for an agency potentially named the National Institute for Development Effectiveness (NIDE) - like a NICE for global health spending by bilateral and multilateral aid agencies. The authors are well placed to propose this agency given their wealth of experience in this area. The paper outlines the need, the proposed mechanism, aspects of establishment, and requirements (e.g. methods and data). The authors pre-emptively outline some potential arguments opposing NIDE and posit the alternative - what would happen if there was no NIDE? They also outline the anticipated costs. 
The authors note that this is not a new idea for the UK (p4) and mention the UK Government's What Works initiative (some aspects of social policy) and NICE (health technology assessment). It might be useful to hear more about what other countries or multilateral agencies may have done in this area especially with regard to establishment, methods, and data sources

It appears that health technology assessment would be a major role for NIDE but it may be worth also considering the costs of scale up and implementing interventions (and not only budget impact analysis).

The authors anticipate some hostility. They mention several aspects but this is based on selected challenges once NIDE would be established. The authors may want to comment on one or two reasons that some may oppose even the establishment of NIDE. There may be several (and possibly competing) imperatives for some particular 'aid' projects funded by government(s). Concerning the negative arguments about 'economics', one can point to NICE itself for the benefits of 'economics'!

The authors helpfully outline what NIDE might cost but it would be instructive to know the amount of money spent on aid - at least by the UK. Indeed, the authors hint at the excellent anticipated return on investment for NIDE - allocation efficiency for aid!

Some particular comments:

P3, col 2 - The authors pose some good information requirements. [“What are missing, and what a NICE-for-aid could provide, are value-for-money indicators and valid, reliable processes for measuring and reporting against them."] but it would be helpful to have some more detail on these vital components.

P4 col 1 - Could mention that the UK government funds the 'What works' initiative (for nonUK audiences).

P4 col 2 - Please define the three Es from the 3E framework.

P5 col 1 - It is unclear about the use of the term 'incidence' (presumably of disease or condition) with its example of (how much of the full cost falls on private individuals)' which seems related to funding sources.

Is the topic of the opinion article discussed accurately in the context of the current literature?

Yes

Are all factual statements correct and adequately supported by citations? Yes

Are arguments sufficiently supported by evidence from the published literature? Yes

Are the conclusions drawn balanced and justified on the basis of the presented arguments? Yes 
Competing Interests: No competing interests were disclosed.

Reviewer Expertise: Health technology assessment and health services research

I confirm that I have read this submission and believe that I have an appropriate level of expertise to confirm that it is of an acceptable scientific standard.

The benefits of publishing with F1000Research:

- Your article is published within days, with no editorial bias

- You can publish traditional articles, null/negative results, case reports, data notes and more

- The peer review process is transparent and collaborative

- Your article is indexed in PubMed after passing peer review

- Dedicated customer support at every stage

For pre-submission enquiries, contact research@f1000.com 